\title{
Paktik Masase dan Konsultasi Kesehatan Pada Car Freeday Kota Mataram
}

\author{
${ }^{1}$ Arif Yanuar Musrifin, ${ }^{2}$ Subagio, ${ }^{3}$ Dadang Warta Chandra WK, ${ }^{4}$ Susi Yundarwati, ${ }^{5}$ Andi \\ Anshari Bausad, ${ }^{6}$ Ismail Marzuki, ${ }^{7}$ Noor Akhmad. \\ ${ }^{1234567}$ Prodi Pendidikan Olahraga dan Kesehatan, \\ Universitas Pendidikan Mandalika-NTB-Indonesia \\ Email arifyanuarmusrifin@ikipmataram.ac.id
}

\begin{abstract}
Abstrak. Analisis kegiatan PKM Praktik masase dan konsultasi kesehatan yang dilaksanakan pada kegiatan car freeday yang ada di jl.udayana Kota Mataram adalah (1) Melalui praktik masase, hal yang diharapkan adalah mengenalkan pentingnya therapy masase, sehingga masyarakat mampu mempraktekkan masase secara sederhana di rumah masing-masing, untuk menjaga kebugaran atau menghilangkan kelelahan. (2) Melalui konsultasi kesehatan, hal yang diharapkan adalah masyarakat harus mempunyai tujuan dari berolahraga dan mengedukasi tentang rasa sakit yang sering dirasakan akibat berolahraga ataupun beraktifitas biasa dan pengobatan yang sederhana, seperti rasa kram pada kaki, salah urat atau sendi akibat salah bergerak, rasa capek dibadan, dan sebagainya. Metode yang dilaksanakan dengan alur Rancangan kegiatan PKM tim akan mendata peserta car freeday yang akan mendapatkan layanan dengan mengisi biodata, apakah ingin mendapatkan praktik masase atau hanya ingin mengkonsultasikan kesehatannya. Setelah selesai mendapatkan pelayanan, peserta kegiatan akan mengisi angket survei kuesioner tentang hasil yang didapatkan setelah mengikuti PKM dan seberapa penting kegiatan ini dilaksanakan. Hasil kegiatan didapatkan prosentase total hasil PKM yang sudah dilaksanakan oleh tim berada dalam kategori baik dengan besaran prosentase hasil $41 \%$, sisanya $30 \%$ berada dalam kategori baik sekali, $29 \%$ kategori cukup. Untuk kategori kurang dan kurang sekali $0 \%$. Kesimpulan PKM (1) Dasar pengetahuan ilmu masase dan pengecekan kesehatan peserta PKM dalam ketegori baik, akan tetapi untuk praktek nya kurang. (2) Kebermanfaatan dan pelayanan kegiatan PKM berada dalam kategori baik (3) Keberlangsungan dalam pelayanan pelaksanaan PKM didaptakan hasil baik.
\end{abstract}

Kata kunci: Petunjuk Penulisan; Jurnal Abdimas; Template Artikel

\section{PENDAHULUAN}

Masase adalah teknik menyentuh dan menekan bagian-bagian tubuh untuk mempengaruhi syaraf dan otot agar mengendur sehingga dapat bekerja secara optimal sesuai dengan fungsinya. Masase akan menimbulkan suatu pengaruh fisiologis dan mekanis yang mendatangkan suatu relaksasi atau rasa sakit yang berkurang akibat adanya pembengkakan (haematome). Selain itu masase juga menimbulkan pengaruh secara psikologis yang dapat menumbuhkan rasa percaya diri (self confidence).

Menurut fungsinya masase dapat digunakan sebagai berikut :

1. Masase untuk tujuan terapi (therapy massage), adalah upaya masase untuk memberikan pengaruh yang baik terhadap suatu kondisi cedera atau penyakit (patologi).
2. Masase kesehatan (hygiene massage), adalah upaya masase untuk memelihara kebugaran tubuh, menormalkan fungsi organ serta menghindarkan diri dari penyakit atau kelainan.

3. Masase olahraga (sport massage), adalah upaya masase dengan menggunakan teknik menipulasi yang bermacammacam untuk memperbaiki dan mempertahankan kondisi tubuh olahragawan serta menghilangkan kelainan-kelainan akibat olahraga yang ditimbulkan.

Terjadinya cedera tidak hanya dialami oleh olahragawan, tetapi masyarakat umum juga sering mengalami, seperti halnya salah posisi tidur atau tergelincir pada saat berjalan. Penaganan pertama dalam cedera penting dilakukan agar cedera yang dialami oleh olahragawan atau pada masyarakat pada umumnya tidak semakin parah, baru tindakan 
medis bisa dilakukan jika dibutuhkan. Dalam penanganan cedera dapat kita lakukan dengan teori RICE, sebagai berikut:

1. R (Rice): mengistirahatkan bagian tubuh yg cedera, menghentikan pergerakan pada tubuh yang cedera.

2. I (Ice): Pendinginan, untuk mengurangi pendarahan pembuluh darah, menyebabkan pembuluh darah ditempat cedera berkontraksi menyempit. Pelaksanaan: meletakkan handuk diatas bagian yang cedera, baru kantong es, atau kepingan es diatas handuk/kain.

3. $\mathrm{C}$ (Compression): Penekanan, guna membatasi pembekakan. Pelaksanaan: dengan pembalut kain elastis yg tdk terlalu kuat, agar alirah darah tdk berhenti. Tanda-tanda aliran darah berhenti : Mati rasa, kejang, dan sakit. Agar kembali hangat, buka kembali balutan, dan pasang kembali balutan selama 3 jam, tiang jam istirrhat 15 menit, agar kulit hangat kembali.

4. E (Elevation): Peninggian, meletakkan bagian tubuh lebih tinggi dari jantung. Berfungsi untuk untuk membantu penyaluran cairan yang berlebih.

Peran masase adalah bahwa masase dapat digunakan dikeseharian masyarakat, dimana mayoritas masyarakat untuk orang tua bekerja di sektor pertanian. Ketika lelah sepulang dari ladang atau kebun dapat melakukan masase sederhana di rumah masing-masing.

Kegiatan car freeday yang dilaksanakan oleh pemerintah kota kota mataram bertepat di sepanjang Jl. Udayana, kegiatan ini dilaksanakan setiap hari minggu mulai pukul 06.00 sampai 09.30, peserta kegiatan ini adlaah masyarakat kota mataram dan sekitarnya dan yang menjadi catatan penting adalah dilarangnya kendaraan bermotor beroperasi di sepanjang jalan yang sudah menjadi kegiatan ini. Dimana kegiatan yang dilakukan oleh masyarakat yang hadir dalam kegiatan tersebut bermacam-macam, mulai berlari, bersepeda, jalan kaki, ataupun memanfaatkan fasilatas olahraga yang ada seperti bermain skate board, bermain bola basket, alat fitnes. Selain itu banyak komunitas yang melaksanakan senam bersama ataupun bermian olahraga tradisional.

Analisis kegiatan PKM Praktik masase dan konsultasi kesehatan yang dilaksanakan pada kegiatan car freeday yang ada di jl.udayana kota mataram bertujuan sebagai berikut:

1. Melalui praktik masase, hal yang diharapkan adalah mengenalkan pentingnya therapy masase, sehingga masyarakat mampu mempraktekkan masase secara sederhana di rumah masing-masing, untuk menjaga kebugaran atau menghilangkan kelelahan.

2. Melalui konsultasi kesehatan, hal yang diharapkan adalah masyarakat harus mempunyai tujuan dari berolahraga dan mengedukasi tentang rasa sakit yang sering dirasakan akibat berolahraga ataupun beraktifitas biasa dan pengobatan yang sederhana, seperti rasa kram pada kaki, salah urat atau sendi akibat salah bergerak, rasa capek dibadan, dan sebagainya.

\section{METODE PELAKSANAAN}

Metode pelaksanaan kegiatan ini dilakukan dengan dua bentuk, yang pertama adalah kegiatan praktik masase dan konsultasi kesehatan akibat berolahraga ataupun beraktifitas sedia kalanya dalamkehidupan sehari-hari. Berikut ini adalah bagan kegiatan yang sudah dilaksanakan.

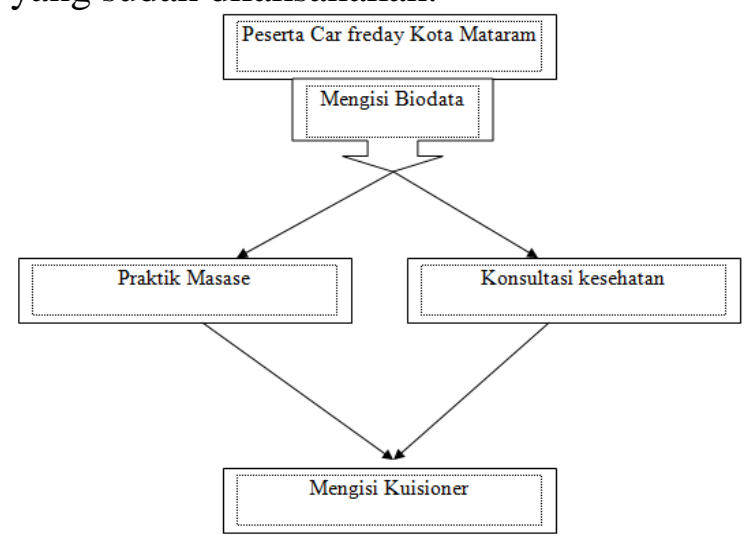

\section{Gambar 1. Rancangan Kegiatan}

Alur Rancangan kegiatan PKM yang akan diksanakan sesuai gambar diatas adalah, tim akan mendata peserta car freeday yang akan mendapatkan layanan dengan mengisi biodata, apakah ingin mendapatkan praktik masase atau hanya ingin mengkonsultasikan 
kesehatannya. Setelah selesai mendapatkan pelayanan, peserta kegiatan akan mengisi angket survei kuesioner tentang hasil yang didapatkan setelah mengikuti PKM dan seberapa penting kegiatan ini dilaksanakan.

Kegiatan PKM ini dibantu oleh mahasiswa prodi pendidikan olahraga dan kesehatan yang telah memprogramkan mata kuliah T/P Masase dan dinyatakan lulus dan layak sebagai measure/measuse oleh dosen pengampu mata kuliah sebanyak 20 mahasiswa. Dimana nantinya akan dibagi menjadi 2 kelompok, disetiap kelompok kelompok 10 mahasiswa. Layanan prantik masase akan disiapkan 5 tempat, dimana setiap 1 tempat akan di layani oleh 2 mahasiswa. Untuk layanan konsultasi kesehatan di sediakan 2 empat dan langsung dilayani oleh tenaga ahli/dosen masase dan fisioteraphy.

Lama kegiatan PKM ini dilaksanakan sebanyak 1 bulan, atau sebanyak 5 kali di setiap hari minggu di kegiatan car freeday kota mataram, dari pukul 07.00 sampai jam 09.00. Data yang akan di peroleh dalam kegiatan ini adalah jumlah data peserta di setiap minggunya dan hasil pengisian angket kuesioner kegiatan PKM, dan data hasil tersebut akan di olah dan analisis.

Soal survey angket kuesioner berisi 20 pertanyaan, dimana 5 soal tentang pentingnya kegiatan PKM dan 10 Soal pengetahuan tentang dasar masase, pengecekan dasar kesehatan dan cedera olahraga, dan 5 soal tentang pelayanan kegiatan, untuk nilai skore maksimal nya adalah 100 dan berikut ini adalah tabel pengkategorian hasil.

Tabel. 1. Pengkategorian Hasil Survey

\begin{tabular}{|c|l|l|}
\hline No & \multicolumn{1}{|c|}{ Kategori } & Skore \\
\hline 1 & Baik Sekali & $80-100$ \\
\hline 2 & Baik & $59-79$ \\
\hline 3 & Cukup & $39-58$ \\
\hline 4 & Kurang & $19-38$ \\
\hline 5 & Kurang sekali & $0-18$ \\
\hline
\end{tabular}

\section{HASIL DAN PEMBAHASAN}

\section{Hasil PKM}

Kegiatan PKM yang telah dilaksanakan selama 1 bulan atau 5 kali, jumlah peserta yang mengikuti kegiatan ini sebagai berikut.

Tabel. 2 Jumlah Peserta PKM

\begin{tabular}{|c|l|c|}
\hline No & Minggu & Jumlah Peserta \\
\hline 1 & Pertama & 34 \\
\hline 2 & Kedua & 36 \\
\hline 3 & Ketiga & 40 \\
\hline 4 & Keempat & 42 \\
\hline 5 & Kelima & 46 \\
\hline & Total & $\mathbf{1 9 8}$ \\
\hline & Rata-Rata & $\mathbf{3 9 , 6}$ \\
\hline
\end{tabular}

Jumlah peserta kegiatan PKM yang dilaksanakan di dapatkan rata-rata di setiap kegiatan yang dilaksanakan sabanyak 39 orang, dan jumlah total yang peserta selama 5 kali kegiatan adalah 198 orang.

Hasil pengisian angket kuesioner yang sudah dibagikan kepada peserta PKM di setiap kegiatan, secara penuh pengisian angkat di dampingi oleh pelaksana kegiatan PKM, dijamin kerahasiannya dan tanpa ada paksaan, Berikut ini adalah rekapitulasi prosentase total hasil PKM yang didapatkan dari data selama 5 kali pelaksanaan kegiatan PKM.

Tabel 3. Prosentase Total Hasil PKM
\begin{tabular}{|l|c|}
\hline Kategori & Prosentase Hasil \\
\hline Baik Sekali & $30 \%$ \\
\hline Baik & $41 \%$ \\
\hline Cukup & $29 \%$ \\
\hline Kurang & 0 \\
\hline Kurang Sekali & 0 \\
\hline & \\
\hline Total & $\mathbf{1 0 0 \%}$ \\
\hline
\end{tabular}

Prosentase total hasil PKM yang sudah dilaksanakan oleh tim berada dalam kategori baik dengan besaran prosentase hasil $41 \%$, sisanya $30 \%$ berada dalam kategori baik sekali, $29 \%$ kategori cukup. Untuk kategori kurang dan kurang sekali $0 \%$. Sehingga hasil kegiatan ini berjalan dengan baik, dan respon atau perhatian oleh peserta car freday juga baik.

\section{PEMBAHASAN}

Melihat dari tabel 2 dari jumlah peserta yang mengikuti PKM, rata-rata usia yang menjadi peserta masih bisa dikatakan masih dalam usia produktif sekitaran usia 35 tahun, sehingga aktifitas olahraga yang dilaksanakan bisa dikatakan masih cukup tinggi. Seharusnya masyarakat biasa pada umumnya harus mempunyai tujuan khusus 
tentang tujunan dia berolahraga, begitu juga dengan pengecekan standart kesehatan yang bisa dilaksanakan sendiri di rumah. Hasil survey dari pengisisan angkat kuesioner dari 10 Soal pengetahuan tentang dasar masase, pengecekan dasar kesehatan dan cedera olahraga, untuk 6 soal tentang masase dan kesehatan cukup baik, dengan skore rata-rata 27, akan tetapi praktik dan pelaksanaan nya kurang, hal ini dapat dilihat dari 4 butir soal pertanyaan tentang tentang tujuan berolahraga dan pengecekan standar kesehatan Analisis situasi yang dilakukan oleh tim, yaitu memberikan pengetahun tentang tujuan berolahraga, apakah untuk rekreasi, kebugaran atau untuk mencapai prestasi, kemudian cara pengecekan standar kebugaran tubuh dengan penghitungan denyut nadi istirahat, denyut nadi latihan dan denyut nadi maksimal. Untuk pengetahuan dasar tentang masase juga bisa dilaksnakan di rumah, seperti halnya masase terapy dnegan merendam kaki dengan air dingin di tambahkan garam, atau tehnik pemijatan sederhana, dengan tehnik eflrurage (mengurut/memijat), petrisage (menekan) dan shaking (menggoncang).

Kebermanfaatan kegiatan PKM yang sudah dilaksanakan dari 5 butir soal tentang pentingnya kegiatan PKM, hasilnya cukup tinggi dengan rata-rata nilai skore 23 , maka kegiatan PKM ini akan direncakanan dilaksanakan di beberapa tempat, seperti di pantai yang ada wilayah utara dan selatan lombok dengan melibatkan alumni. Sehingga tujuan khusus kegiatan ini adalah masyarakat mempunyai tingkat kesehatan dan kebugaran yang baik, melalui kegiatan praktik masase dan konsultasi kesehatan.

Keberlangsungan dalam pelayanan pelaksanaan PKM didaptakan hasil baik, dengan nilai rata-rata 21 , dari 5 butir pertanyaan. Hal ini dikarenakan manfaat secara langsung di badan setelah mengikuti pratik masase dan pelayanan yang ramah serta cukup bersabahat dengan para petugas masase maupun tim konsultasi kesehatan.

Pada saat sekarang ini banyak orang yang kurang memiliki gaya hidup yang baik, seperti pola makan, tidur, dan olahraga yang dilakukan dengan tidak benar. Makan tanpa melihat dengan kandungan gizi dan waktu makan yang baik, karena ingin menurunkan berat badan, mengurangi makan karena ingin mendapatkan berat badan ideal secara cepat. Menjaga pola makan sangat penting agar kita dapat mengatur sesuai dengan kebutuhan tubuh. Selain menjaga pola makan hal penting lainnya adalah melakukan aktivitas olahraga.

Aktifitas olahraga juga demikian, hanya sebatas mengikuti musim, orang suka bersepeda ikut bersepeda, atau hanya sekedar datang ke acara car freeday. Padahal sesungguhkan aktifitas olahraga banyak memberi manfaat apabila dilaksanakan yang baik dan memiliki tujuan yang jelas. Olahraga merupakan gerakan olah tubuh yang memberikan efek pada tubuh secara keseluruhan. Olahraga membantu merangsang otot-otot dan bagian tubuh lainnya untuk bergerak. Otot-otot menjadi terlatih, sirkulasi darah dan oksigen dalam tubuh pun menjadi lancar sehingga metabolisme tubuh menjadi optimal.

\section{KESIMPULAN}

Kesimpulan PKM yang sudah dilaksanakan sebagai berikut

1. Dasar pengetahuan ilmu masase dan pengecekan kesehatan peserta PKM dalam ketegori baik, akan tetapi untuk praktek nya kurang, atau bisa dikatakan bahwa masyarakat lebih suka pergi pusat spa atau masase dibandingkan mempraktikan sendiri dirumah. Begitu juga dengan pengecekan kesehatan secara sederhana, seperti mengecek denyut nadi istirahat maupun denyut ndai maksimal secara rutin, tidak pernah dilaksanakan, meskipun sudah mengetahui cara melaksanakannya.

2. Kebermanfaatan dan pelayanan kegiatan PKM berada dalam kategori baik.

3. Keberlangsungan dalam pelayanan pelaksanaan PKM didaptakan hasil baik.

\section{SARAN}

Gagasan yang akan dilaksanakan selanjutnya adalah memperbanyak kegiatan yang melibatkan pemuda di wilayah wisata yang ada di lombok, sehingga masyarakat daerah wisata mempunyai kemampuan terkait masase dan pengetahuan dasar tentang 
kesehatan dan berani mendirikan sebuah tempat usaha baru tentang masase dengan pelaku utama masyarakat sekitar. Hal yang berkaitan dengan hambatan kegiatan adalah evaluasi peserta PKM setelah mengikuti kegiatan apakah benar diaplikasikan dalam kehiduapan sehari-harinya.

\section{UCAPAN TERIMA KASIH}

Ucapan terima kasih yang sebesarbesarnya atas dukungan baik secara materi dan suport secara langsung dengan ikut hadir dalam kegiatan PKM disampaikan kepada,

1. Rektor UNDIKMA, Wakil rektor 1 dan 2, Kabiro Humas

2. Dekan FIKKM, Wakil dekan 1 dan 2

3. Kaprodi Pendidikan Olahraga dan kesehatan

\section{DAFTAR PUSTAKA}

Bessy Sitorus Pane.2015. Peranan Olahraga Dalam Meningkatkan Kesehatan. Jurnal Pengabdian Kepada Masyarakat Vol. 21 Nomor 79 Tahun XXI Maret 2015.

Dewi Fitriani, 2018. Pengaruh Massage Effleurage Terhadap Penurunan Tekanan Darah Pada Penderita Hipertensi Di Wilayah Puskesmas Bakti Jaya Setu Tangerang Selatan. Edudharma Journal Vol 2 No.2, September 2018

Graha S, Ali dan Bambang Priyonoadi. 2008.
Terapi Massage
Frirage
(Penatalaksanaan Cedera pada Anggota Gerak Tubuh Bagian Atas). Yogyakarta: Fakultas Ilmu Keolahragaan universitas Neregi Yogyakarta.

Haikal Millah, dkk. 2018. Sosialisasi Aturan Berolahraga Yang Benar Sesuai Dengan Rumus "TKPE”. Jurnal Pengabdian Siliwangi, Volume 4, Nomor 2, Tahun 2018.

Ibrahim, Nurhadi (2007). Anatomy and Physiology of Musculoskeletal.Jakarta Diklat Pengembangan SDM Kemenpora.

Priyonoadi, Bambang. 2008. Sport Massage (Massage Olahraga). Yogyakarta: Fakultas Ilmu Keolahragaan universitas Neregi Yogyakarta.
Roepajadi, Joesoef, 2009. Masase Olahraga. Surabaya: Universitas Negeri Surabaya Pres.

Soemardiawan \& Mujriah, 2014. Masage Sport Segment. Mataram: Genius

Sri Nuraini, 2016. Pelatihan Massage Bagi Eks Tenaga Kerja Indonesia diSubang Jawa Barat. Jurnal Sarwahita Volume 13 N0. 1.

Slamet Junaidi,Yulingga Nanda Hanief,Dkk, 2017. Pelatihan Massage Kebugaran Sebagai Media Untuk Menciptakan Peluang Usaha Bagi Remaja Karang Taruna Di Desa Ngulankulon Kabupaten Trenggalek. Jurnal ABDINUS, Vol 1 No 1. 